\title{
A reciclagem do lixo urbano como fonte de renda, e a preservação dos recursos naturais e ambientais
}

Alair Ambrósio do Nascimento alairconsultoria@hotmail.com Pontifícia Universidade Católica de Goiás (PUC-GO), Goiânia, GO, Brasil

\section{Rafael Jesus de Oliveira} rafaeljesusoli@yahoo.com.br Pontifícia Universidade Católica de Goiás (PUC-GO), Goiânia, GO, Brasil

José Elmo de Menezes jelmo@pucgoias.edu.b Pontifícia Universidade Católica de Goiás (PUC-GO), Goiânia, GO, Brasil

\author{
RESUMO
}

Este estudo tem por objetivo discutir os impactos sociais e de renda causados pela reciclagem do lixo urbano na cidade de Goiânia, a partir da reutilização da matéria prima aplicada na elaboração de novos produtos próprios para o consumo humano, e os benefícios causados ao meio ambiente com a preservação das fontes de recursos naturais, e a redução da disposição inadequada do lixo no solo. 0 trabalho pesquisou a atuação das cooperativas de catadores de materiais recicláveis sob os seguintes aspectos: estrutura física das cooperativas, as condições de trabalho dos cooperados, a formação das cooperativas em redes, as parcerias firmadas com poder público municipal, os aspectos documental e legal. A pesquisa utilizada foi de natureza exploratória qualitativa e quantitativa, o universo de atores entrevistados foi composto por membros da Prefeitura Municipal de Goiânia, como representantes da Agencia Municipal do Meio Ambiente (AMMA), e da Companhia de Urbanização de Goiânia (COMURG), Membro da Incubadora Social da Universidade Federal de Goiás (UFG), e representantes das quatorze cooperativas de catadores de materiais recicláveis cadastradas pela Prefeitura Municipal de Goiânia.

PALAVRAS-CHAVE: Coleta seletiva. Resíduos sólidos urbanos. Reciclagem. Cooperativismo. 


\section{INTRODUÇÃO}

O lixo urbano tornou-se um dos maiores desafios para os gestores públicos a nível mundial, a escalada de crescimento dos resíduos sólidos urbanos (RSU) no Brasil, vem superando o crescimento populacional tornando-se um dos principais problemas dos centros urbanos. A acessibilidade da sociedade a novos produtos, aliadas as mudanças de hábitos de consumo das gerações, tem sido apontado como fator determinante para o crescimento da geração e acúmulo do lixo, tornando-se um forte apelo sócio/ambiental pela preservação do meio ambiente e das fontes de recursos naturais.

Estas discussões ampliam os horizontes de estudos com foco na gestão e gerenciamento dos resíduos sólidos urbanos, com vistas a atender o que dispõe a Lei 12.305/2010 da Política Nacional dos Resíduos Sólidos (PNRS), e a prestação dos serviços públicos de limpeza urbana e o correto manejo de resíduos sólidos conforme determina a Lei Federal de Saneamento Básico (Lei no 11.445/2007).

Estudos realizados pela Associação Brasileira de Empresas de Limpeza Pública e Resíduos Especiais ABRELPE apontaram que os brasileiros geraram aproximadamente 76.387.200 toneladas (RSU) em 2013, indicando crescimento na geração de lixo em $4,1 \%$ sobre 2012 , enquanto que no mesmo período a população cresceu em torno de 3,7\% (IBGE 2013).

Baseado nas informações percebe-se a importância do tema na atualidade, assim esta pesquisa buscou avaliar os serviços da coleta seletiva no município de Goiânia, capital do estado de Goiás, e a destinação dos rejeitos como matéria prima para fabricação de novos produtos próprios para o consumo humano; conforme estimativa do IBGE (2015), a cidade possui uma população estimada em 1.430.69 habitantes, este crescimento pode ser facilmente percebido com o aumento da produção do lixo destinados ao aterro sanitário, e às empresas e cooperativas de catadores cadastradas pelo município.

O Programa Goiânia Coleta Seletiva (PGCS) foi instituído pela Prefeitura no ano de 2008, cuja responsabilidade pela execução acompanhamento e desenvolvimento dos serviços, foi atribuído à Companhia de Urbanização de Goiânia (COMURG), a qual é também a responsável pela coleta dos resíduos sólidos domésticos dentro do município.

Diante da percepção do aumento na produção de lixo em Goiânia, o município busca estabelecer parcerias com outros segmentos da sociedade no sentido dar aos rejeitos recicláveis uma destinação correta, proporcionando a estes o retorno para as linhas de produção, além de reduzir a ocupação do aterro sanitário.

Diante disso discute-se em que pese a destinação dos rejeitos para as empresas de reciclagem, e as cooperativas de catadores na cidade de Goiânia, e os benefícios resultantes dessas ações ao meio ambiente. 
REVISÃO BIBLIOGRÁFICA

\section{Responsabilidade Compartilhada}

A responsabilidade compartilhada pelo ciclo de vida dos produtos, é o conjunto de atribuições individualizadas e encadeadas que passam por vários caminhos começando pelos fabricantes, passando pelos importadores, distribuidores, comerciantes, consumidores seguindo até os gestores dos serviços públicos como, a limpeza urbana e manejo dos resíduos sólidos de forma adequada, (PNRS).

As empresas que exploram os rejeitos recicláveis, assim como as cooperativas de catadores de materiais recicláveis, surgem num momento de percepção em que as relações de parcerias entre o poder público, sociedade organizada, e empresas, devem somar esforços no sentido de assumirem suas responsabilidades sócio econômico/ambientais, trazendo como proposta um novo modelo de gestão compartilhada de forma mais flexível e participativa, cujo objetivo é dar a destinação ambientalmente correta aos rejeitos, maximizando seus lucros além de potencializar suas relações com fornecedores e clientes, e assim atender as necessidades de seus colaboradores, e associados que dependem dos lucros para suas subsistências.

Reorganizar suas estratégias de trabalho de cooperação, significa introduzir novas propostas em busca de melhores vantagens competitivas de seus produtos e serviços, com visão organizacional mais flexível e participativa, visando alcançar melhores resultados com menores custos, compartilhando riscos, para maximização dos lucros.

O CEMPRE (2010), aponta que a coleta possibilita a deposição dos resíduos sólidos urbanos (RSU), de forma participativa e ambientalmente correta, e dentre as diversas formas de coleta destaca que:

Muitas cidades não têm condições de recolher e / ou dispor de seus resíduos adequadamente em aterros sanitários; os municípios tendem a deixar que boa parte dos seus rejeitos sejam jogados em locais inadequados, gerando em determinadas partes das cidades o trabalho da cata informal (TAHIR et al., 2011), destaca ainda que, a coleta com a participação dos catadores, consiste na utilização do trabalho dos catadores organizados em cooperativas ou associação, bem como os catadores autônomos, apoiados pelo poder público ou não, os quais recolhem os materiais recicláveis dispostos em via pública, segregados ou não, oriundos de domicílios ou estabelecimentos comerciais ou empresas doadoras, utilizando-se de carrinhos de tração manual ou de transporte veicular.

A ameaça causada pela ação dos resíduos sólidos depositados de forma inadequada no ambiente requer ações efetivas que minimizem os impactos e neutralizem as transformações ambientais: Tais ações podem ser simples e objetivas, porém possíveis de alcançar os objetivos desejados tais como:

"Investir no desenvolvimento, na fabricação e na colocação no mercado de produto que após seu uso possa ser reutilizado, reciclado, ou que seja possível dar a ele a destinação ambientalmente correta, possibilitando assim a geração de menos resíduos sólidos. 
Divulgar informações quanto a forma de evitar, reciclar, e eliminar os (RSU).

Recolher os produtos e resíduos após o uso, e dar aos recicláveis a destinação ambientalmente correta, à logística reversa.

Participar das ações previstas no Plano Municipal de Gestão Integrada de Resíduos Sólidos, quando firmados acordos ou termos de compromisso com o município, no caso de produtos ainda não inclusos no sistema de logística reversa" (Oliveira, 2010 p.35/36).

A coleta de resíduos sólidos não é visto como apenas o desejo de vê-los distantes dos locais onde foram gerados, com finalidade de evitar a proliferação de insetos como, moscas, baratas, ratos, dentre outros, reconhecidamente como transmissores de doenças como, febre, diarreia, leptospirose, etc; o devido afastamento para locais adequados é garantia de boa gestão, e o cumprimento no que determina a Lei 12,305/2010, Política Nacional dos Resíduos Sólidos, (PNRS), quanto a destinação ambientalmente correta dos resíduos sólidos urbanos.

Ao responder a pergunta levantada neste estudo, percebe-se que o modelo de gestão compartilhada eleva a credibilidade das organizações envolvidas, tanto do poder público, quanto das empresas e cooperativas envolvidas, dessa forma algumas organizações buscam fortalecer suas estruturas com intuito de tornar-se mais competitivas, haja vista que como em qualquer mercado, o poder de barganha tende a aumentar quando se tem mais vantagens competitivas.

O estudo mostrou que as cooperativas do município de Goiânia procuram fortalecimento organizando-se em redes, que de acordo com Amato (1998), "a formação de redes de cooperação surge como uma alternativa inovadora e estratégica nas empresas, opondo-se à concepção verticalizada e fragmentada da cadeia produtiva, " e ocorre em organizações de todo o porte, mas é em pequenas e médias empresas que aparecem maiores vantagens tais como:

- Elevar o poder de competitividade: criando relações mais confiantes com seus fornecedores e clientes, pequenas e médias empresas podem concorrer de forma mais equilibrada com grandes empresas.

- Dividir riscos e custos: somando os investimentos iniciais menores a união de pequenas e médias empresas dividem também eventuais riscos, assim o prejuízo ficará diluído entre elas fazendo com que essas empresas se adaptem melhor às mudanças de mercado.

- Maior transferência de informação e tecnologia: permite que as pequenas e médias empresas estejam sempre se atualizando em todos os aspectos, uma vez que a velocidade de transferência de informações é muito grande.

A motivação para a formação de redes geralmente se refere aos ganhos de competitividade de cada uma das cooperativas de catadores a qual ela está ligada por exemplo; quanto maior for sua participação de mercado, maior será o poder de competição, quanto maior a redução de custos, maior a combinação de recursos, divisão de riscos e incertezas, a coordenação de atividades e preços e troca de clientes estratégicos (POWELL, 2007).

"As redes de empresas atrelam-se à administração das operações estratégicas e à busca do posicionamento competitivo para toda a rede coletiva, pressupondo forte integração interorganizacional e coesão massiva dos processos de negócios das empresas. Nas redes prevalece a focalização dos negócios e a flexibilidade coletiva 
incrementando-se, continuamente, a rentabilidade das empresas, através de uma gama estreita de processos, tecnologia de produto e core business". (BARBOSA \& SACOMANO,2001).

De acordo com o Plano Nacional de Saneamento Básico - (PLANSAB), o plano estrutural que compõe a limpeza urbana e manejo de (RSU), compreende: "as atividades infraestruturas e instalações operacionais de coleta, transporte, transbordo, tratamento e disposição final do lixo doméstico e do lixo originário da varrição e limpeza de logradouros e vias públicas".

Jardim e Wells (1995), afirma que em média, o lixo doméstico no Brasil, é composto por $65 \%$ de matéria orgânica; $25 \%$ de papel; $4 \%$ de metal; $3 \%$ de vidro e $3 \%$ de plástico. Apesar de atender a legislação específica de cada município, a geração de lixo comercial de até $50 \mathrm{~kg}$ ou litros por dia, são de responsabilidades das prefeituras, enquanto os demais são de responsabilidade do próprio gerador.

\section{Logística Reversa}

Segundo Zikmund e Staton, apud Felizardo e Hatakeyama (2005, p. 3), a conceituação mais antiga sobre logística reversa teve início nos anos 70, cuja aplicação dos conceitos de distribuição, são voltados para o processo inverso com o objetivo de se atender às necessidades de recolhimento de materiais resultantes do pós-consumo e pós-venda.

O conceito da logística reversa exprime o cerne da discussão deste assunto, visto que os rejeitos ao voltarem para a linha de produção torna-se em novos produtos que serão consumidos pelo homem.

Chaves e Martins (2005), apontam que o crescimento da logística reversa nas operações de logística empresarial é motivado pelo crescimento do mercado e o grande potencial econômico que possui o processo logístico reverso e que no momento não tem sido explorado como deveria.

Ao contrário da logística direta, a logística reversa ainda não dispõe de uma estrutura suficiente para fazer fluir de forma eficiente os produtos/resíduos gerados pela cadeia produtiva.

Lambert e Stock (1981), apud Felizardo e Hatakeyama, (2005, p. 2), destacaram a logística reversa como: "[...] o produto seguindo na contramão de uma rua de sentido único pela qual a grande maioria dos embarques de produtos flui em uma direção". Nesta conceituação percebe-se a logística reversa fazendo o sentido contrário ao da logística direta, Pitágoras, Moreira e Bonfim (2013, p.2).

Segundo Leite (2003), a logística reversa pode ser entendida como:

[...] área da logística empresarial que planeja, opera e controla o fluxo e as informações logísticas correspondentes, do retorno dos bens de pós-vendas e de pós-consumo ao ciclo de negócios ou ao ciclo produtivo, por meio dos canais de distribuição reversos, agregandoIhes valor de diversas naturezas: econômica, ecológica, legal, logístico, de imagem corporativa, entre outros (Leite, 2003, pp. 1617). 
Resíduos Sólidos Urbanos - RSU - Conceitos e Princípios

As discussões sobre a problemática dos resíduos sólidos urbanos (RSU), teve maior ênfase na década de 70 quando diversos estudiosos despertaram para o crescimento acelerado dos resíduos sólidos urbanos (RSU), quando então vários autores passaram a definir os resíduos sólidos de acordo com suas conclusões e entendimentos.

Com a implantação da Política Nacional dos Resíduos Sólidos (PNRS), o assunto ganhou apoio dos organismos de proteção ambiental, reforçou as ações do governo quanto as políticas públicas e quanto ao uso dos recursos naturais, com foco na proteção do solo, subsolo e as nascentes, e atribuiu maior poder de fiscalização dos órgãos públicos.

Pela lei $n^{\circ} 12.305 / 2010$, os entes federativos que desejarem acessar recursos da União deverão elaborar seus respectivos planos de resíduos sólidos, implantar a coleta seletiva, promovendo a reciclagem dos resíduos sólidos, a disposição final ambientalmente adequada dos rejeitos em aterro sanitário como também a eliminação dos lixões.

\section{O Programa de Coleta Celetiva no Município de Goiânia}

O Programa Goiânia Coleta Seletiva, (PGCS), foi criado em 2008 pelo Decreto Municipal número 754 pelo então Prefeito Iris Rezende Machado, e faz parte de Plano de Gestão de Resíduos Sólidos (PGRS).

O programa foi aprovado pelo Plano Diretor de Goiânia e tem por objetivo atribuir responsabilidade aos segmentos da sociedade implantando nas pessoas uma nova forma de pensar e agir em relação ao consumo consciente, onde o subprograma 1 busca o envolvimento da sociedade no programa da coleta seletiva, o subprograma 2 , trabalha a coleta seletiva no setor educacional, o subprograma 3 , promove a coleta seletiva nas diversas regiões geográficas da cidade, conforme mostra a Figura 1.

Figura 1 - Programa Goiânia de Coleta seletiva

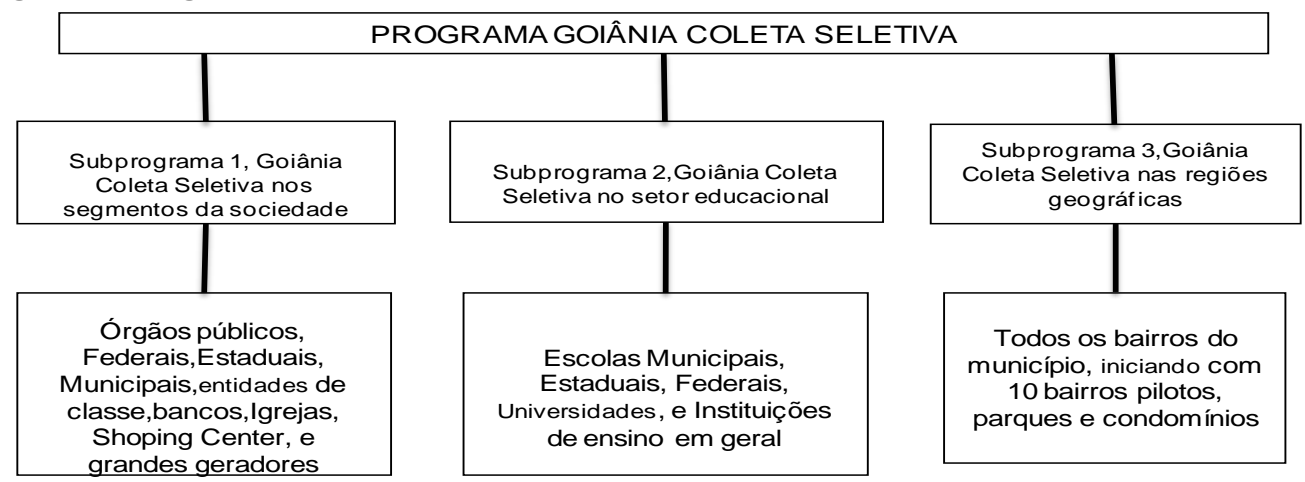

Fonte: Agência Municipal do Meio Ambiente - AMMA (2013).

Com o processo de coleta seletiva foi possível diagnosticar diversos ganhos como:

1) Ganhos ambientais: 
- Aumento da vida útil do Aterro Sanitário, a partir da redução de resíduos que deixarão de ser encaminhados ao mesmo, ao serem comercializado por meio de reutilização ou reciclagem destes materiais;

- Aumento do ciclo de vida das matérias-primas coletadas;

- Redução do volume de gases colaboradores do efeito estufa que seriam lançados na atmosfera com a queima a céu aberto, atualmente realizada no aterro sanitário;

2) Ganhos Educacionais:

- Estímulo a mudança de hábitos e valores no que respeito à proteção ambiental e conservação da vida;

3) Ganhos Culturais:

- Criação de novas práticas de separação dos resíduos, considerando que os materiais recicláveis permeiam por todas as atividades sociais;

4) Ganhos Sociais:

- Geração de trabalho e renda aos catadores de materiais recicláveis;

- Resgate da cidadania dos catadores por meio de sua organização em cooperativas;

5) Ganhos Econômicos:

- Redução de gastos com aterramento dos resíduos;

- Geração de rendimentos financeiros a partir da aquisição de créditos de carbono;

- Diminuição de gastos com a limpeza pública;

- Abertura de novos postos de trabalho formal para os catadores de materiais recicláveis.

\section{Apresentação dos Dados}

Para a realização dos serviços da coleta seletiva no município de Goiânia, a Prefeitura disponibiliza 83 Pontos de entrega voluntaria (PEVs), e conta com a estrutura conforme apresentado através da Tabela 1: 
Tabela 1 - Estrutura disponibilizada pela prefeitura de Goiânia para a coleta seletiva

\begin{tabular}{ccccc|c} 
Caminhões baú & PEVs & Rotas/ circuitos & $\begin{array}{c}\text { Cooperativas } \\
\text { atendidas }\end{array}$ & $\begin{array}{c}\text { Lixo recolhido em } \\
2014 / \text { ton/dia }\end{array}$ \\
\hline 15 & 129 & 119 & 14 & 2.500 \\
\hline
\end{tabular}

Fonte: Companhia de Urbanização de Goiânia - COMURG (2016).

A prefeitura firmou parceria com as cooperativas de catadores do município no sentido de entregar os materiais recicláveis recolhidos pela coleta seletiva diretamente às cooperativas formais sem nenhum custo, reduzindo assim as despesas com transportes para as cooperativas, o que de certa forma torna seus preços mais competitivos no mercado. Esta parceria vem apresentando bons resultados, apesar de ainda existirem falhas no programa da coleta seletiva, como a falta de recolhimento dos rejeitos em domicilio nas datas programadas, o que acaba sendo motivo de muitas reclamações dos chamados pequenos geradores, a exemplo da dona de casa.

A tabela 2 apresenta a relação das cooperativas formais cadastradas pela prefeitura de Goiânia, a quantidade de materiais recicláveis que são recolhidos diariamente no município, e a empregabilidade gerada. O levantamento foi realizado em visitas in loco por este pesquisador, entre os dias 26 de setembro a 24 de outubro de 2015, em entrevistas realizadas com os representantes das cooperativas cadastradas pela prefeitura conforme Tabela 2.

Tabela 2 - Análise de correlação entre as variáveis de entrada

\begin{tabular}{|c|c|c|c|c|}
\hline & $\frac{3}{\frac{8}{8}}$ & $\frac{8}{\frac{8}{2}}$ & 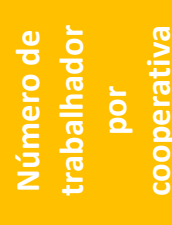 & 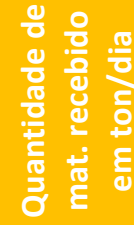 \\
\hline 01 & $\begin{array}{c}\text { A AMBIENTAL-Cooperativa } \\
\text { de catadores de Materiais } \\
\text { Recicláveis }\end{array}$ & $\begin{array}{c}\text { Rua } 2 \text { Qd chácara } 32 \text { área } \\
\text { cond. Anhanguera } \\
\text { Goiânia }\end{array}$ & 10 & 3,5 \\
\hline 02 & $\begin{array}{l}\text { ACOP-Associação de } \\
\text { Catadores de Mat. } \\
\text { Recicláveis Ordem e } \\
\text { Progresso }\end{array}$ & $\begin{array}{c}\text { Av.das Américas c/ Rua } \\
\text { SAB 03,St.Albino } \\
\text { Boaventura, }\end{array}$ & 12 & 1,5 \\
\hline 03 & $\begin{array}{c}\text { Beija-Flor-Cooperativa de } \\
\text { Catadores de Mat.Recicláveis }\end{array}$ & $\begin{array}{c}\text { Rua João Luiz de Almeida } \\
\text { Qd } 5 \text { Lts } 11 \text { e } 12 \text { Crimeia } \\
\text { Oeste: }\end{array}$ & 22 & 5,0 \\
\hline 04 & $\begin{array}{c}\text { COOCAMARE-Grupo de } \\
\text { Catadores de Mat.Recicláveis }\end{array}$ & $\begin{array}{c}\text { Rua } 3 \text { Qd D Lt chácara } \\
\text { retiro: }\end{array}$ & 21 & 5,0 \\
\hline 05 & $\begin{array}{l}\text { COOPER-RAMA-Grupo de } \\
\text { Cat.de Mat.Recicláveis. }\end{array}$ & $\begin{array}{c}\text { Rua JC 66,Qd } 145 \text { Lt } 18 \text { Jd } \\
\text { Curitiba III, }\end{array}$ & 22 & 4,0 \\
\hline 06 & $\begin{array}{c}\text { COOPER-FAMI-Grupo de Cat. } \\
\text { De Mat.Recicláveis }\end{array}$ & $\begin{array}{c}\text { Rodovia } 060 \text { nr 92, Km } 04 \\
\text { chácara Maringá }\end{array}$ & 13 & 4,0 \\
\hline 07 & $\begin{array}{l}\text { COOPERLIMPE-Cooperativa } \\
\text { de Cat.de Mat.Recicláveis }\end{array}$ & $\begin{array}{l}\text { Rua Jandira Chacara 139, } \\
\text { sitio dos ipês }\end{array}$ & 10 & 6,0 \\
\hline 08 & $\begin{array}{l}\text { COOPER-MAS- Cooperativa } \\
\text { de Cat. de mat. Recicláveis } \\
\text { "Meio Ambiente Saudável" }\end{array}$ & $\begin{array}{l}\text { Av.Senandor Canedo nr } \\
31 \text { Conj.Vera Cruz I }\end{array}$ & 15 & 4,5 \\
\hline
\end{tabular}




\begin{tabular}{|c|c|c|c|c|}
\hline & $\frac{3}{\frac{20}{20}}$ & \& & 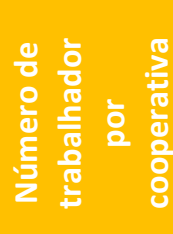 & 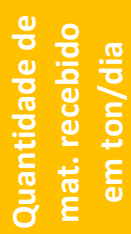 \\
\hline 09 & $\begin{array}{l}\text { COOPREC-Grupo de Cat.de } \\
\text { Mat.Recicláveis }\end{array}$ & $\begin{array}{l}\text { Rua São José esq.Rua } \\
\text { Goiás Qd DF Lt } 16 \text { Jd } \\
\text { Conquista, }\end{array}$ & 17 & 2,5 \\
\hline 10 & $\begin{array}{l}\text { FÊNIX CARROSSEL-Grupo de } \\
\text { Cat.de Mat.Recicláveis }\end{array}$ & $\begin{array}{c}\text { Rua Belém Qd } 119 \text { It } 776 \\
\text { Jd Petrópolis, }\end{array}$ & 18 & 5,0 \\
\hline 11 & $\begin{array}{l}\text { GOIÂNIA VIVA-Grupo de } \\
\text { Cat.de mat.Recicláveis }\end{array}$ & $\begin{array}{c}\text { Rodovia 060,qd } 8 \text { Lt } 10 \\
\text { Recanto dos Funcionários } \\
\text { Públicos }\end{array}$ & 28 & 5,0 \\
\hline 12 & $\begin{array}{l}\text { NOVA ESPERANÇA-Grupo de } \\
\text { Cat.de Mat.Recicláveis }\end{array}$ & $\begin{array}{l}\text { Av.JacarandáQd } 16 \text { Lt 03, } \\
\text { Jd Botanico, Buena vista }\end{array}$ & 10 & 3,5 \\
\hline 13 & $\begin{array}{l}\text { SELETA-Cooperativa de } \\
\text { Cat.de Mat.Recicláveis }\end{array}$ & $\begin{array}{l}\text { Av. Uruguaiana Qd } 31 \text { Lt } \\
08 \text { Jd N.Mundo, }\end{array}$ & 17 & 2,5 \\
\hline 14 & $\begin{array}{c}\text { CARRINHO DE OURO - Grupo } \\
\text { de Catadores .de Materiais } \\
\text { Recicláveis }\end{array}$ & $\begin{array}{l}\text { Rua } 02 \text { Qd } 08 \text { Lt 07, } \\
\text { Jardim fortaleza, }\end{array}$ & 10 & 2,5 \\
\hline & Total & & 225 & 54,5 \\
\hline
\end{tabular}

Fonte: Levantamento realizado por este pesquisador junto a Prefeitura de Goiânia (2015).

A quantidade de materiais recebidos pelas cooperativas foi informada em caminhões/dia, onde foram considerados 500 quilos de materiais por caminhão em média, posteriormente convertidos em toneladas.

O levantamento da quantidade de materiais destinados a reciclagem foi realizado junto a COMURG, e nas quatorze cooperativas de catadores na cidade de Goiânia, GO; o tipo de pesquisa utilizado foi o Survey, cuja escolha para esta metodologia deve-se ao fato dela fornecer na sua obtenção de dados ou nas informações, as características ou as opiniões de determinado grupo de pessoas indicado como representante de uma população-alvo, e foi utilizado questionário como instrumento de pesquisa. Em levantamento realizado junto a Companhia de Urbanização de Goiânia (COMURG), na cidade de Goiânia foram identificados atualmente "Quatorze cooperativas" em atividades, desta maneira a pesquisa realizada englobou $100 \%$ de seu campo amostral, tendo a participação de todas as cooperativas citadas pela entidade fiscalizadora na cidade de Goiânia.

A pesquisa mostrou que os serviços de coleta seletiva de materiais recicláveis em Goiânia, ainda mostra falhas estruturais devido a descontinuidade dos serviços da coleta, fato observado in loco quando a comunidade ao encaminhar os materiais para os PEVs, estes não sendo recolhidos nos dias programados, acabam sendo contaminados pela ação da chuvas, ou mesmo por catadores independentes que selecionam os materiais que lhes interessam, espalhando o restante pelas calçadas, que acabam sendo levados pelas enxurradas entupindo as galerias pluviais da cidade.

Outro ponto falho observado na pesquisa foi a desmotivação da população, que ao separar os materiais em casa, estes não sendo colhidos nos dias programados pelos serviços da coleta seletiva, a dona de casa acaba colocando-o junto ao lixo orgânico, o que acaba sendo coletado pelo caminhão do lixo comum e encaminhado para o aterro sanitário. 
Outra percepção foi quanto ao desperdício dos materiais recicláveis dentro de algumas cooperativas, que por falta de estrutura adequada perdem chegam a perder $50 \%$ de materiais já dentro das cooperativas, devido a exposição ao sol e chuva. Este fato gera desmotivação dos catadores pois além da perda dos materiais, ainda gera a perda dos serviços dos catadores que precisa reclassificar os materiais danificados e encaminhá-los ao aterro sanitário.

A falta de estrutura como cobertura adequada traz prejuízos aos catadores, uma vez que o material sendo contaminado precisa ser separados e encaminhados ao aterro sanitário, o requer muitas horas de trabalho dos cooperados, que do ponto de vista financeiro torna-se inútil haja vista que os ganhos financeiros são medidos pela quantidade de material segregados e em condições de venda.

O Gráfico 1, mostra o percentual de materiais aproveitados pelas cooperativas de catadores.

Gráfico 1 - Percentual de aproveitamento por cooperativa

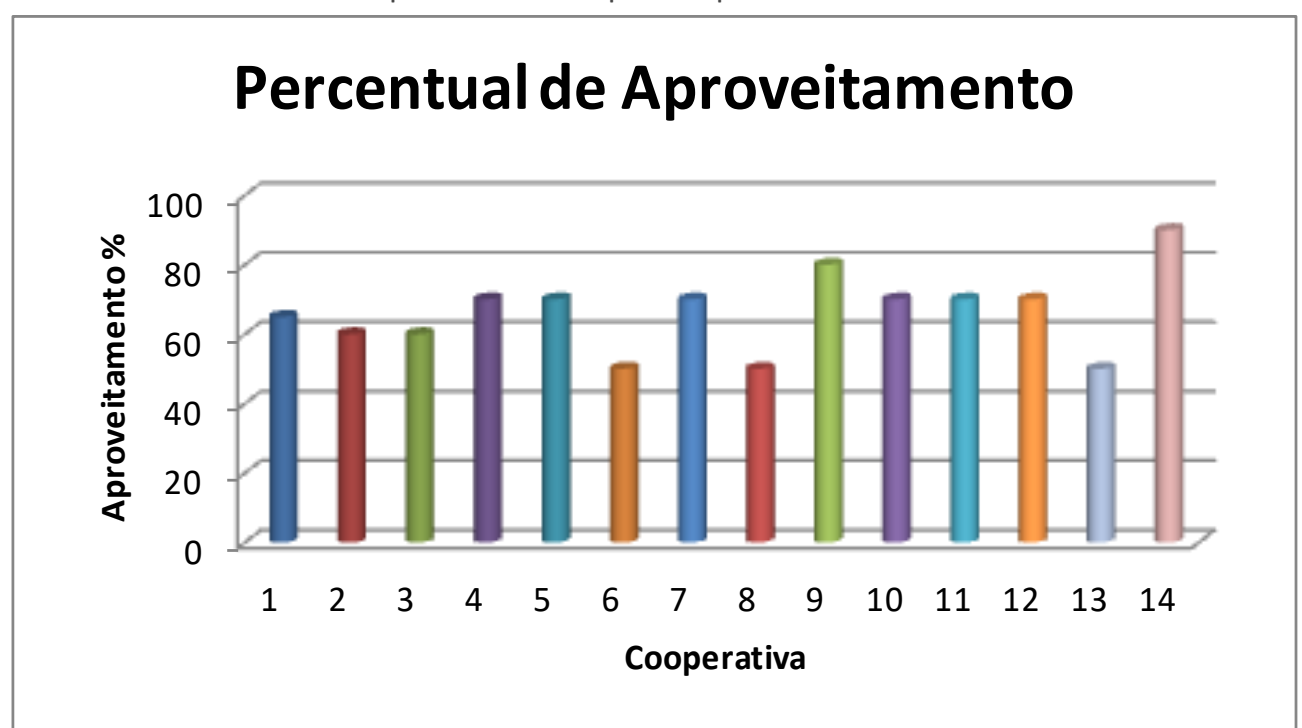

Fonte: Cooperativa de catadores de Goiânia (2015).

Das quatorze cooperativas cadastradas pele prefeitura de Goiânia, nove ou $35,70 \%$ disseram que o período seco garante melhores ganhos devido à baixa umidade presente em alguns materiais, além do que os materiais que chegam no período seco são de melhor qualidade.

Para as cooperativas que não dispõe de cobertura, ou dispõe de forma insuficiente, a chegada de materiais no período chuvoso gera transtornos e perdas causando desmotivação, devido ao acumulo nos pátios das cooperativas e a rotatividade dos trabalhadores.

Foi possível observar in loco que muitos trabalhadores não fazem uso dos equipamentos de proteção contra acidentes, chamados de Equipamentos de Proteção Individual (EPI), em entrevista com o Presidente de uma das Cooperativas, os trabalhadores são orientados a fazerem uso de uniformes, no entanto, a maior parte deles preferem não utilizar alguns dos equipamentos como luvas e máscaras de proteção de boca e nariz, por considerar desnecessária ou pelo desconforto causados pelo uso destes. 
Segundo os entrevistados, é muito comum pequenos acidentes como cortes nas mãos provocados por materiais cortantes como cacos de vidros, lâmpadas quebradas, ou pequenos estilhaços de metais, o que na maior das vezes eles não procuram postos de saúde para fazer curativos ou tomar vacinas anti tetânica por exemplo.

Nem todas as cooperativas possuem equipamentos para prensar materiais como papelão, garrafas pet, jornais, plásticos etc. Segundo os atores entrevistados as vantagens do uso deste equipamento estão na redução do tamanho dos volumes, uma vez prensados os materiais diminui a área de utilização dentro da cooperativa, facilita o manuseio, reduz o espaço físico dentro dos caminhões ao serem transportados, agregando mais valor ao produto devido a redução dos custos com transportes.

Algumas cooperativas apresentam boas condições de trabalho, com galpões, esteiras de separação, gaiolas de acondicionamento dos materiais segregados, banheiros, masculinos e femininos, cozinha com geladeira, fogão, mobiliários, e com ambiente para refeições, boa ventilação, e boa luminosidade deixando o ambiente mais agradável, , este cenário reflete positivamente no resultado e na produtividade, melhorando a auto estima, dos trabalhadores, no relacionamento inter pessoal, e consequentemente no aumento da renda salarial no final do mês.

Estas cooperativas representam 35,71\%, enquanto que 64,29\% não dispõe de todas as condições necessárias para o bom desempenho do trabalho.

Segundo os Presidentes das Cooperativas entrevistadas afirmam que se as prefeituras disponibilizassem linhas de créditos especificas com juros subsidiados para cooperativas adquirirem seus equipamentos, isto tornaria a atividade mais rentável e mais prazerosa do ponto de vista de satisfação dos trabalhadores, além do que poderia contribuir muito mais com os aspectos ambientais e sociais, gerando novos postos de trabalho.

Um representante de cooperativa entrevistado, relata que os trabalhos das cooperativas precisam de mais apoio por parte do poder executivo, visto que a maioria das cooperativas não dispõe de condições estruturais adequadas para receber os materiais vindos da coleta seletiva, ficando expostos ao sol e a chuva, o que compromete a qualidade dos materiais, e em alguns casos chegando a atingir $50 \%$ de perdas, resultando na redução dos valores no momento da venda.

No Gráfico 2, é demonstrado o percentual de participação da cadeia de fornecimento de materiais recicláveis para as cooperativas de catadores no município de Goiânia. 
Gráfico 2 - Principais fornecedores de material reciclável para as cooperativas

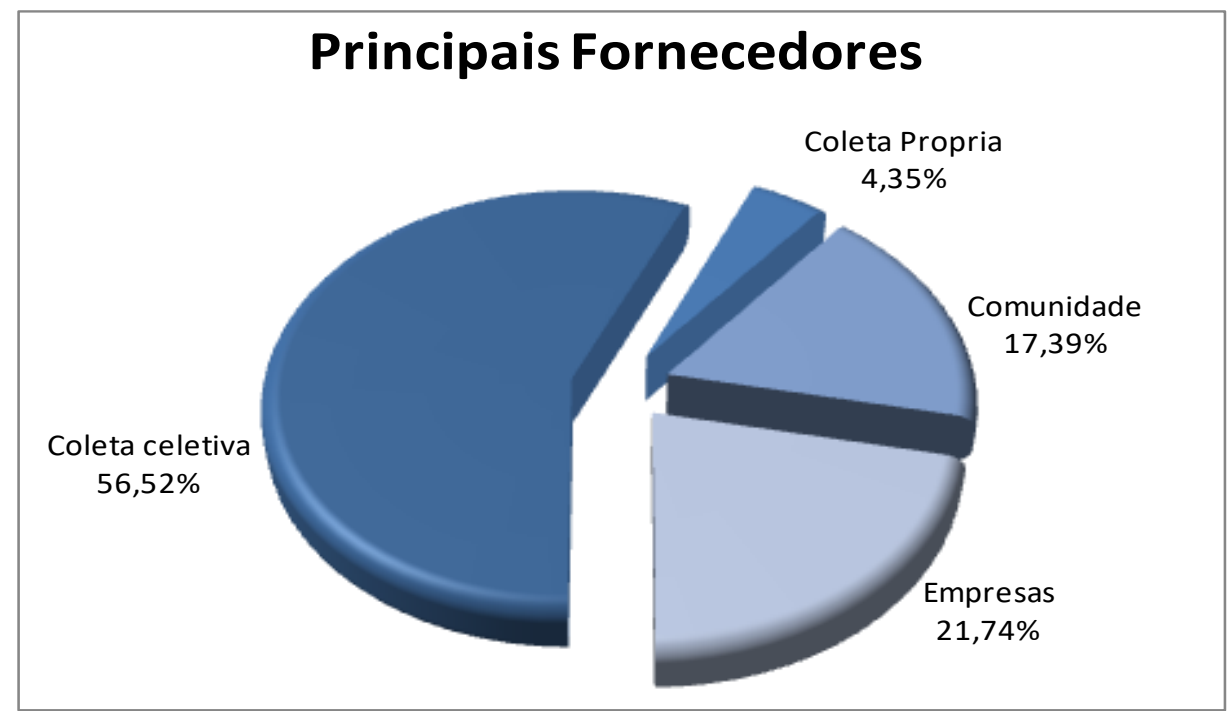

Fonte: Cooperativa de catadores de Goiânia (2015).

O estudo mostrou que a reciclagem vem assumindo um importante papel sócio/econômico e ambiental, pois a transformação dos rejeitos, resulta em novos produtos, poupa as fontes de recursos naturais, reduz a quantidade de materiais encaminhados para o aterro sanitário, gera emprego e renda a muitas famílias de baixa renda, e promove a integração entre cooperados, proporcionando as famílias envolvidas a inserção no mercado de trabalho e de consumo.

Na Tabela 3 é apresentado a média de trabalhadores cooperados nas quatorze cooperativas pesquisadas no município, evidenciando sua importância como fator de empregabilidade as famílias que vivem da cata.

Tabela 3 - Número de trabalhadores por cooperativa

\begin{tabular}{cccccccc} 
Mínimo & 19 Quartil & Média & Mediana & 3@ Quartil & Máximo & $\begin{array}{c}\text { Desvio } \\
\text { Padrão }\end{array}$ \\
\hline 10 & 10 & 16,071429 & 16 & 21,25 & 28 & 5,663164 \\
\hline
\end{tabular}

Fonte: Autoria própria (2017).

Já a Tabela 4, apresenta a média de faturamento por cooperativa, embora a maior parte delas ainda funcionem de forma irregular quanto aos aspectos documentais e legais, e desprovidas de boas condições estruturais e equipamentos, nota-se que há um faturamento mediano atraente para seus gestores e cooperados.

Tabela 4 - Número de trabalhadores por cooperativa

\begin{tabular}{ccccccc} 
Mínimo & 10 Quartil & Média & Mediana & 3@ Quartil & Máximo & $\begin{array}{c}\text { Desvio } \\
\text { Padrão }\end{array}$ \\
\hline 8.000 & 12.000 & $15.961,5385$ & 15.000 & 20.000 & 27.500 & $6.339,2348$ \\
\hline
\end{tabular}

Fonte: Autoria própria (2017). 
As visitas e entrevistas, mostrou que $68 \%$ dos trabalhadores em cooperativas são mulheres, contra $32 \%$ da força de trabalho masculina, foi constatado na pesquisa que esta expressiva presença feminina tem sua origem em fatos sociais, pois em sua maioria são separadas e mães com filhos ainda menores de idade sob seus cuidados, e que devida a dificuldade de formação e capacitação utilizam a reciclagem como fonte de renda e a rotatividade de trabalho entre as mulheres é menor que entre os homens. Outro ponto enfatizado por todos os representantes de cooperativas é que, ainda é grande a discriminação social pela atividade de catadores, um dos entrevistados diz:

"nós prestamos um grande serviço à sociedade, retiramos das suas portas o lixo, retiramos do meio ambiente materiais que levariam até 200 anos para se decompor, geramos emprego e renda para diversas famílias muitas delas vindas das ruas, alguns alcoólatras ou dependentes de drogas, apesar de todo nossos esforços ainda somos vistos como lixeiros, pessoas que realizam trabalho sujo, anti-higiênico, sem credibilidade e incapacitadas para pagar compromissos, isso dificulta nosso acesso a créditos como empréstimos em bancos por exemplo ou mesmo alugar uma área para instalação da cooperativa ou comprar equipamentos necessários para o trabalho".

As quatorze cooperativas organizadas no município de Goiânia juntas empregam 225 trabalhadores, cuja média salarial é de 1,3 salários mensais por trabalhador, somente duas apresentam índices médios próximos a 2 salários, outras três sequer atingem a margem de 1 salário por cooperado. Conforme demonstrado através do Gráfico 3.

Gráfico 3 - Renda média mensal dos trabalhadores cooperados da cooperativa de catadores de Goiânia

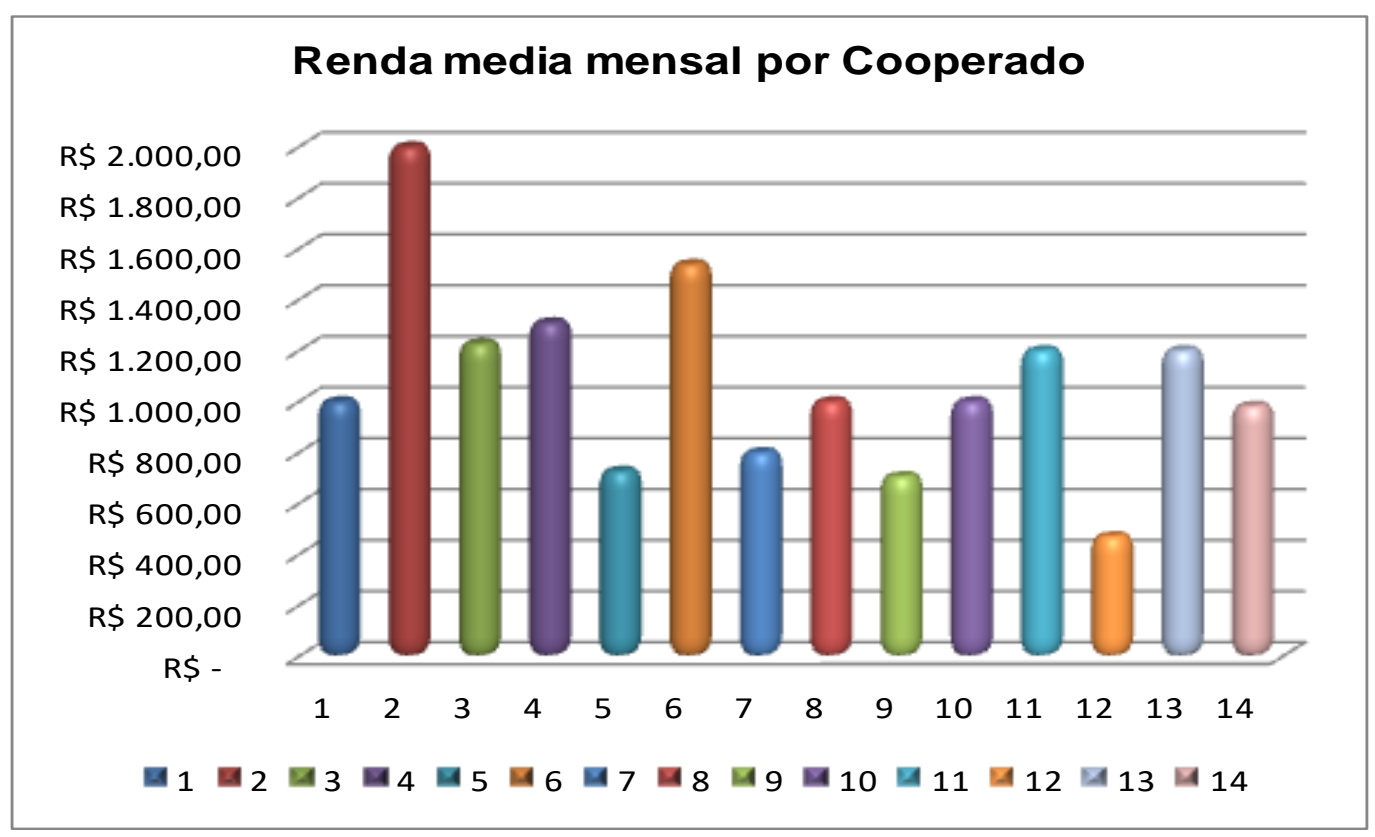

Fonte: Cooperativa de catadores de Goiânia (2015).

Os Presidentes das Cooperativas entrevistados são unânimes quando concordam que para solucionar a questão do lixo em especial o reciclável na grande Goiânia, o caminho mais curto é a prefeitura criar campanhas especificas e permanentes de tal forma a fazer a comunidade se envolver no processo, desde a 
separação até a destinação final de forma correta dos rejeitos recicláveis, e dar subsídios para que as cooperativas de catadores tenham condições de trabalhar com a máxima capacidade de aproveitamento dos rejeito reduzindo e as perdas.

\section{CONSIDERAÇÕES FINAIS}

A pesquisa mostrou que a reciclagem é o caminho certo para redução dos rejeitos recicláveis, e redução das áreas contaminadas pela sua disposição irregular no meio ambiente. Mostrou também que a presença das cooperativas de catadores no processo de reaproveitamento dos rejeitos vem contribuindo de forma positiva com o município de Goiânia, quando elas juntas recebem 54,5 toneladas diariamente de materiais vindos da coleta seletiva, ou seja; cerca de $11 \%$ de todo material reciclável recolhido pelos serviços da coleta seletiva da prefeitura. A pesquisa mostrou também que ainda há falhas nos serviços da coleta no município, e que ainda é grande a perda de materiais que chegam às cooperativas, em média $30 \%$, devido à falta de estrutura física no processo de segregação e acondicionamento, sendo que em alguns casos esta perda pode chegar a 50\% mesmo depois de depositados nos pátios das cooperativas, e que com medidas certas apoiadas pelo poder público, este índice poderá ser reduzido, incrementando o lucro das famílias que vivem desta atividade. 


\title{
The Recycling of Urban Waste as a Source of Income, and the Preservation of Natural Resources and Environmental
}

\begin{abstract}
This study aims at discussing the social and income impacts caused by the recycling of urban waste in the city of Goiânia, based on the reuse of the raw material used in the elaboration of new products suitable for human consumption, and the benefits caused to the environment by The preservation of natural resources, and the reduction of inadequate waste disposal in the soil. The work investigated the activities of recyclable material collectors' cooperatives under the following aspects: physical structure of cooperatives, working conditions of cooperatives, formation of cooperatives in networks, partnerships with municipal authorities, documentary and legal aspects. The research used was of a qualitative and quantitative exploratory nature, the universe of actors interviewed was composed of members of the Municipality of Goiânia, as representatives of the Municipal Environmental Agency (AMMA), and of the Urbanization Company of Goiânia (COMURG), Member of the Social Incubator of the Federal University of Goiás (UFG), and representatives of the fourteen cooperatives of collectors of recyclable materials registered by the Municipality of Goiânia.
\end{abstract}

KEYWORDS: Selective collect. Urban solid waste. Recycling. Cooperativism. 


\section{REFERÊNCIAS}

AMATO, J. N. Terceirização e mudança organizacional: o desafio de um novo padrão de relacionamento entre empresas. Anais... CLADEA -1995:

Administração de Serviços. São Paulo-Brasil. 1998.

ASSOCIAÇÃO BRASILEIRA DE EMPRESAS DE LIMPEZA PÚBLICA E RESÍDUOS ESPECIAIS - ABRELPE. Panorama dos resíduos sólidos no Brasil - 2013. 11ㅇed. São Paulo: ABRELPE, 2014.

CHAVES, G. L. D.; MARTINS, R. S. Diagnóstico da logística reversa na cadeia de suprimentos de alimentos processados no oeste paranaense. Anais... In: VIII Simpósio de Administração da Produção, Logística e Operações Internacionais (SIMPOI), ago. 2005, São Paulo. Anais. São Paulo: FGV, 2005.

LEITE, P. R. Logística Reversa - Meio ambiente e Competitividade. São Paulo: Prentice Hall, 2003.

FELIZARDO, J. M., HATAKEYAMA, K. A Logística Reversa nas Operações Industriais no Setor de Material Plástico: Um estudo de caso na cidade de Curitiba. Anais... In: XXIX Encontro da ANPAD (ENANPAD), set. 2005, Brasília. Anais... Brasília, 2005.

JARDIM, N. S.; WELLS, C. (Org.).Lixo Municipal: Manual de Gerenciamento integrado. São Paulo: IPT: CEMPRE, 1995.

PLANSAB - Plano Nacional de Saneamento Básico 2013, Disponível em: $<$ www.mma.gov.br/cidades, http://www4.cidades.gov.br/consulta_plansab/src/sistema/index>. Acesso em: 11 nov. 2014.

POLÍTICA NACIONAL DE RESÍDUOS SÓLIDOS. Agora é lei: Novos desafios para poder público, empresas, catadores e população. Publicação do Compromisso Empresarial para Reciclagem (CEMPRE). São Paulo - SP. Disponível em: <http://www.cempre.org.br/download/pnrs_002.pdf >. Acesso em: 12.nov.2014.

POWELL, W. Hybrid organisational arrangements: new form or transitional Development?. California Management Review, v. 30, p. 67-87, 2007. 
Recebido: 03 set. 2016

Aprovado: 01 fev. 2017

DOI: $10.3895 /$ gi.v13n1.4597

Como citar:

NASCIMENTO, A. A.; OLIVEIRA, R. J.; MENEZES, J. E. A reciclagem do lixo urbano como fonte de renda, e a preservação dos recursos naturais e ambientais. R. Gest. Industr., Ponta Grossa, v. 13, n. 1, p. 22-37, jan./mar. 2017. Disponível em: <https://periodicos.utfpr.edu.br/rgi>. Acesso em: XXX.

Correspondência:

Alair Ambrósio do Nascimento

Avenida Universitária, 1069, Setor Universitario - 74605010, Goiânia, GO, Brasil - Caixa-postal: 86

Direito autoral: Este artigo está licenciado sob os termos da Licença Creative Commons-Atribuição 4.0 Internacional.

(c) (1) 